\title{
Comores. Gabusi et ndzendze de Mohéli
}

Enregistrements : Abdallah Chihabiddine, Salim Ali Amir, Werner

Graebner (1998). Dizim Records, 1999

Jobonina Montoya-Razafindrakoto

\section{(2) OpenEdition}

1 Journals

Édition électronique

URL : http://journals.openedition.org/ethnomusicologie/776

ISSN : 2235-7688

Éditeur

ADEM - Ateliers d'ethnomusicologie

Édition imprimée

Date de publication : 1 janvier 2001

Pagination : 264-265

ISBN : 2-8257-0723-6

ISSN : 1662-372X

Référence électronique

Jobonina Montoya-Razafındrakoto, « Comores. Gabusi et ndzendze de Mohéli », Cahiers

d'ethnomusicologie [En ligne], 13 | 2001, mis en ligne le 09 janvier 2012, consulté le 20 avril 2019. URL : http://journals.openedition.org/ethnomusicologie/776

Ce document a été généré automatiquement le 20 avril 2019.

Tous droits réservés 


\title{
Comores. Gabusi et ndzendze de Mohéli
}

\author{
Enregistrements : Abdallah Chihabiddine, Salim Ali Amir, Werner \\ Graebner (1998). Dizim Records, 1999
}

Jobonina Montoya-Razafindrakoto

\section{RÉFÉRENCE}

Comores. Gabusi et ndzendze de Mohéli. Enregistrements : Abdallah Chihabiddine, Salim Ali Amir, Werner Graebner (1998). Textes (en français et en anglais) : Werner Graebner ; sommaire des chansons : Abdallah Chihabiddine. 1 CD Dizim Records 4503, 1999.

1 Le choix du mariage comme thème unique de ce $\mathrm{CD}$ est une excellente idée, car le mariage est une cérémonie importante, notamment dans les cultures à forte tradition religieuse. La présentation du livret est agréable, mais son contenu présente certaines lacunes. En effet, on aurait aimé avoir davantage d'informations sur le déroulement même du mariage aux Comores, d'autant plus que les documents présentés ici s'y rapportent exclusivement.

2 Les enregistrements sont de qualité ; toutefois, la prise de son réalisée en studio laisse une impression de «vide» sur le caractère festif ou solennel du mariage. D'une façon générale, on ne perçoit pas véritablement comment ces musiques s'insèrent dans la cérémonie car rien ne nous indique de quelle manière les pièces évoluent par rapport au déroulement du mariage. Il aurait été intéressant de connaître la fonction de ces chants : initier, conseiller le couple sur sa future vie conjugale ? D'après la traduction des textes, les plages $1,4,5,8$, 9 et 10 se rapportent de façon plus ou moins explicite au thème du mariage, alors que nous percevons difficilement le lien sémantique des plages 2, 3, 6 et 7 avec le thème traité. De même, rien ne précise si le morceau plage 5 , apparemment bien connu de la population comorienne, fait partie intégrante d'un répertoire établi ou s'il a été composé par les musiciens. Il n'est pas exclu en effet d'imaginer faire appel à ces derniers pour leur talent d'interprètes mais aussi de compositeurs et d'improvisateurs. Si ces chants étaient chorégraphiés, il aurait fallu également préciser le nom des danses 
correspondantes, pourtant énumérées au début du livret, et en donner la signification. Enfin, on aurait souhaité connaître l'importance et la fonction des instruments utilisés, savoir si la formation instrumentale demeure fixe. Par exemple, l'omniprésence du gabusi dans les pièces 1, 4, 5, 8 et 9 permet-elle de penser qu'il s'agit d'un instrument de circonstance doté d'un rôle symbolique ? Bien que ces questions primordiales subsistent, quelques remarques peuvent être faites sur les instruments de musique.

3 L'utilisation d'instruments que l'on retrouve dans les îles voisines ne parait pas étonnante. En particulier, la proximité géographique des Comores avec Madagascar a favorisé l'immigration de nombreux Comoriens vers sa côte nord-ouest, dans la région du Boina. Les Comoriens côtoyent la population sakalava tout en restant attachés à la culture islamique: en témoignent les mosquées implantées dans cette province malgache. Le ndzenze n'est pas exactement l'homologue de la valiha de Madagascar, traditionnellement montée sur un tuyau de bambou, mais plutôt une réplique de la valiha vata («cithare valise ») de forme parallélépipédique qui, à Madagascar, présente l'avantage de recourir à un matériau de fabrication tel que le bois dans les régions où le bambou pousse peu ou pas; le ndzenze ne comprend ici que quelques cordes métalliques disposées de part et d'autre de la caisse. Par ailleurs, l'implantation de commerçants arabes dès le xi\%o siècle dans l'Océan Indien explique la présence d'un instrument comme le luth : le gabusi des Comores est aussi connu sous le nom de kabosa ou kabosy à Madagascar. La forme arrondie de la caisse de résonance du gabusi et sa table d'harmonie tendue de peau correspondent à un modèle de facture ancienne, aujourd'hui disparu à Madagascar. Enfin, le hochet en radeau est un accessoire également présent dans les musiques de circonstances de Madagascar et de la Réunion où il est communément appelé mkayamba, kaiamba ou kayamb. Ici, tous les instruments accompagnent essentiellement la voix.

Les imperfections du livret n'amoindrissent en rien la qualité de jeu des instrumentistes et des chanteurs, et nous pouvons souligner le fait que ces enregistrements ont le mérite de faire une incursion dans un archipel de l'Océan Indien où l'édition phonographique est encore limitée, comparée aux îles voisines. 